\title{
Performative Interaction in Public Space
}

Lone Koefoed Hansen

Dept of Aesthetic Studies

Aarhus University, Denmark

koefoed@hum.au.dk

\section{Julie Rico}

Dept of Computing Science

University of Glasgow, UK

julie@dcs.gla.ac.uk

\section{Guilio Jacucci}

Helsinki Institute for Information

Technology HIIT

Aalto University, Finland

giulio.jacucci@hiit.fi

Stephen Brewster

School of Computing Science

University of Glasgow, UK

stephen.brewster@glasgow.ac.uk

\section{Daniel Ashbrook}

New Mobile Forms and Experiences

Nokia Research Center Hollywood, CA

daniel.ashbrook@nokia.com

\begin{abstract}
Building on the assumption that every human action in public space has a performative aspect, this workshop seeks to explore issues of interactions with technology in public settings. More and more interfaces are used in public on an everyday basis. Simultaneously, metaphors from performance and theatre studies find their way into research on these interfaces, addressing how interaction with technology can be understood in a performative sense. However, the term 'performativity' is rarely addressed in ways that accentuate its nuances and its analytic power, and this is the focus of the workshop. We will examine the design of performative technologies, the evaluation of user experience, the importance of spectator and performer roles, and the social acceptability of performative actions in public spaces.
\end{abstract}

\section{Categories and Subject Descriptors}

H.5.2 User Interfaces: User-centered design, Theory and Methods, J.4 Social and Behavioral Sciences: Sociology.

\section{General Terms}

Design, Human Factors.

\section{Author Keywords}

Social Acceptability, Spectator Experience, User Experience, Mobility, Performative Interaction. 


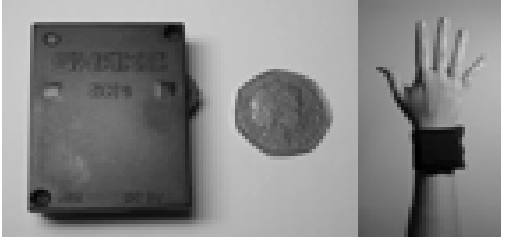

Figure 1. Sensors (such as the SHAKE [10] that contains accelerometer, magnetometer, and gyroscope) can be worn on different places of the body to capture movement.

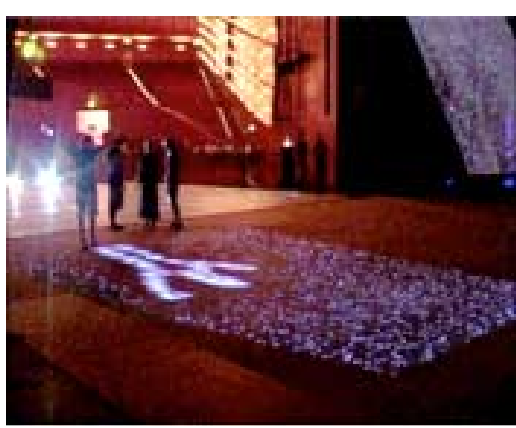

Figure 2. Multimodal art installations in public space brings visitors to performative roles [5].

\section{Introduction}

The increasing amount of interfaces being used in a public context (in interactive installations, as well as in mobile and wearable devices), calls for studying interaction as a public practice. Recent interface examples include interactive public screens [8], multimodal art installations [5], wearable sensing devices to augment entertainment experiences [12] and mobile devices that can be used as props thanks to sensors [14]. Often, performative or theatrical metaphors have accompanied the development of these experiences with technology [12]. The workshop seeks to qualify the use of these metaphors further.

The workshop aims at attracting concurrent research within both theoretical and constructive fields that contribute to the discussion around the workshop's main themes. In particular we are interested in exploring how interface technologies (e.g. multimodal, ubiquitous, and wearable interfaces) shape, choreograph, and/or articulate mobility and performative interactions in public settings.

\section{Theoretical background}

The term "performance" can be understood in many ways, from Goffman's idea that all everyday acts are performative acts [2][3], over it being a staged 'act' with clear demarcations [11] to a processual sense of bringing to completion [4]. When viewing interaction from a performance perspective, the experience of technology and interfaces then also becomes a matter of actively or passively participating in a performance for oneself and/or for others.
Reeves et al. [9] present a taxonomy with four broad design strategies for the performer's manipulations of an interface and their resulting effects on spectators. In response to this, Dalsgaard and Hansen [1] observe that a central facet of aesthetics of interaction is users' experience of themselves "performing their perception".

\section{Workshop Themes}

In light of the above theoretical background, three main interpretations of 'performance' and 'performativity' are likely to interweave:

- everyday performances (inspired by Goffman's seminal work). E.g. the social acceptability of technology related actions in public spaces; appropriations of

UX discussions as well as spectator and performer roles in interaction.

- staged/explicit performances (inspired by performance studies and possibly phenomenology) E.g. using 'performativity' as a term that allows for a rich understanding of how, and under which circumstances, people interact with technology.

- explorative interfaces. E.g. interfaces that are intentionally designed for a playful discovery of its affordances or subversive interfaces addressing use and perception of interfaces (e.g. inspired by critical design).

In light of these understandings of performance and performativity, the workshop will address four main aspects of performative interactions in public spaces. 


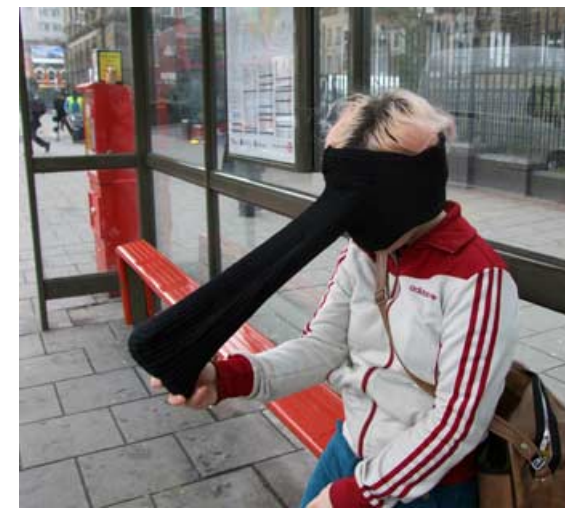

Figure 3. Artworks, such as this scarf that shields an individual's phone from observers [6], highlight how using technology in public and mobile settings is convenient while also requiring users to socially negotiate their public and private spaces.
Technologies for performative interaction

A variety of interface technologies can shape and contribute to performative interaction in various ways. Computer vision can be used to track objects, bodily movements, and facial expressions; microphones can track and process sound, and wearable sensors and devices can be used to interpret gestures and their expressivity. However, performative interaction is not only supported by input, but also by multimodal processing and by output solutions. In fact, tangible interfaces such as multitouch are characterized by unifying input (control) and output (representation). The augmentation of input signals creates feedback loops that in turn affect the performative interactions.

\section{Evaluating user experience}

User experiences in public space are closely related to the feeling, emotional experience, and satisfaction of the interaction, which makes design and evaluation hereof a major issue. The experience is highly dependent on the context where the interaction is taking place and it develops and changes over time with repeated exposure to the interaction [7]. Identifying important user experience issues and evaluating them in an effective way is thus a difficult issue for designers.

Spectator / Performer Roles

Given the variety of settings where interfaces are used, the presence of the spectator plays an important role in the performance (cf. Theoretical Background above). Many interaction design interfaces are explicitly or implicitly influenced by 'audiences' and when the interface is almost always 'on the move' in public space, new challenges for interaction design arise.
Social Acceptability

Since performative interactions put users in public spotlight, the social acceptability is evaluated by the user before, during, and after the 'performance'. Issues of space and time become important, as do the ways that users make decisions about how to act with technology in public space. Research into the social impact of performative technology is, however, limited [10].

\section{Workshop Goals}

The workshop is relevant to media theorists, practitioners and/or designers interested in:

- Gestural interaction and on-body sensing (e.g. wearable computing/sensing, Wii, Kinect and proprietary systems)

- Interactive media art (e.g. installations, performances or mobile experiences)

- Public screens or installations (e.g. in public squares, airports, theme parks and science museums) - Interfaces for use in public (e.g. kiosks, tangible and mobile interfaces)

We encourage paper submissions that explore work-inprogress or early results that reflect upon any of the main workshop themes. For example, accounts of novel interactive technologies; evaluations of user experience in public settings; analyses of purely theoretical aspects such as spectator and performer roles or frameworks for understanding the relationship between public settings and interaction design; and empirical or theoretical studies of social acceptability of technology use in public settings. Preference will be given to submissions that outline works-in-progress or early results. 
The workshop will aim to facilitate the following outputs:

- Workshop Results: A summary of the workshop discussions and results will be made available in a poster format during the conference.

- Network: The setting up of a network of researchers and practitioners who are interested in performative interactions with and around technology in public settings with a view to forming future collaborations and publications.

- Website: A workshop website has been created that will host the results of the workshop. Accepted papers will also be made available on the workshop website: http://www.digitalurbanliving.dk/pips.php

\section{Acknowledgments}

This work is supported by a National Science Foundation Graduate Research Fellowship, a donation from Nokia, the EPSRC project (EP/F023405), and the Danish Council for Strategic Research, 09-063245, (Digital Urban Living).

\section{References}

[1] Dalsgaard, P., Hansen L.K., Performing Perception-Staging Aesthetics of Interaction, ACM TOCHI 15(3), 2008.

[2] Goffman, E., The Presentation of Self in Everyday Life. Penguin Books, London, 1959.

[3] Goffman, E., Behaviour in Public Space; notes on the social organisation of gatherings. Free Press of Glencoe, New York, 1966.

[4] Jacucci, G., Interaction as Performance. Oulu University Press, 2004.
[5] Jacucci, G., Spagnolli A., Chalambalakis, A., Morrison A., Liikkanen, L., Roveda S., and Bertoncini, M. Bodily Explorations in Space: Social Experience of a Multimodal Art Installation, Proc. INTERACT 2009, Springer, 2009, 62-75.

[6] Malia, J. Private Public (Knitted artwork), 2006.

[7] Law, E. L., Roto, V., Hassenzahl, M., Vermeeren, A. P., and Kort, J., Understanding, scoping and defining user experience: a survey approach. In Proc. CHI 2009, ACM Press (2009), New York, NY, 719-728.

[8] Peltonen, P., Kurvinen, E., Salovaara, A., Jacucci, G., Ilmonen, T., Evans, J., Oulasvirta, A. and Saarikko, P. "It's Mine, Don't Touch!": Interactions at a Large Multi-Touch Display in a City Centre. In Proc. CHI 2008 ACM Press (2008), New York, 1285-1294.

[9] Reeves, S., Benford, S., O'Malley, C., and Fraser, M., Designing the spectator experience. In Proc. CHI 2005. ACM Press (2005), New York, NY, 741-750.

[10] Rico, J., and Brewster, S. Usable Gestures for Mobile Interfaces: Evaluating for Social Acceptability. In Proc. CHI 2010, ACM Press (2010), New York, NY, 887896.

[11] Schechner, R. Performance theory. Routledge, London, 1998.

[12] Schnädelbach, H., Rennick Egglestone, S., Reeves, S., Benford, S., Walker, B., and Wright, M., Performing thrill: designing telemetry systems and spectator interfaces for amusement rides. In Proc. CHI '08. ACM Press (2008), New York, NY, 1167-1176.

[13] Sheridan, J.G. et al., Understanding Interaction in Ubiquitous Guerrilla Performances in Playful Arenas. In Pro. British HCI '04, Springer-Verlag (2004), 3-17.

[14] Sundström, P., Ståhl, A., and Höök, K., In situ informants exploring an emotional mobile messaging system in their everyday practice. Int. J. Hum.-Comput. Stud. 65, 4 (Apr. 2007), 388-403. 